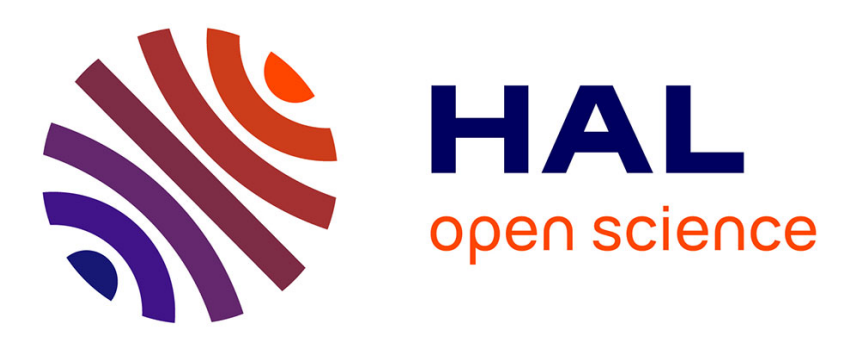

\title{
Consulting citizens: technologies of elicitation and the mobility of publics
}

\author{
Javier Lezaun, Linda Soneryd
}

\section{To cite this version:}

Javier Lezaun, Linda Soneryd. Consulting citizens: technologies of elicitation and the mobility of publics. Public Understanding of Science, 2007, 16 (3), pp.279-297. 10.1177/0963662507079371. hal-00571132

\section{HAL Id: hal-00571132 \\ https://hal.science/hal-00571132}

Submitted on 1 Mar 2011

HAL is a multi-disciplinary open access archive for the deposit and dissemination of scientific research documents, whether they are published or not. The documents may come from teaching and research institutions in France or abroad, or from public or private research centers.
L'archive ouverte pluridisciplinaire HAL, est destinée au dépôt et à la diffusion de documents scientifiques de niveau recherche, publiés ou non, émanant des établissements d'enseignement et de recherche français ou étrangers, des laboratoires publics ou privés. 


\title{
Consulting citizens: technologies of elicitation and the mobility of publics
}

\author{
Javier Lezaun and Linda Soneryd
}

The new centrality of "the public" to the governance of science and technology has been accompanied by a widespread use of public consultation mechanisms designed to elicit from citizens relevant opinions on technoscientific matters. This paper explores the configuration of legitimate constituencies in two such exercises: the UK "GM Nation?" public debate on food biotechnology, and a Swedish "Transparency Forum" on the risks of mobile telephones. We consider the apparently paradoxical combination in these two examples of a tendency to produce static images of the public with a high valuation of mobility — of citizens and their opinions — as the key outcome of deliberation. We discuss the organizers' careful delineation of a distinction between "stakeholders" and the "general public," and their aversion to any sort of "eventfulness" in public deliberations. Finally, we introduce the classical notion of the "idiot" - the individual who minds exclusively his or her own private affairsand argue for the need to develop a new vocabulary to evaluate the politics of "listening to the public."

\section{Introduction: public controversies and technologies of elicitation}

"The public is always right"; or, at the very least, it is always right to listen to what the public has to say when devising new policies concerning controversial science and technology. The desire to seek lay views has become a sort of new orthodoxy in the governance of technoscience (Irwin and Michael, 2003; Irwin, 2006; STAGE, 2005). This ambition to listen applies particularly to reticent publics: the "hard to hear" constituencies that are deemed excluded from the often cacophonous public debates.

From the point of view of government, two premises seem to underlie the ambition to elicit public views: that lay publics can contribute useful insights, knowledge and values to decisions that are inextricably political (Wynne, 2001), and that extending participation and consultation throughout the policy process, all the way to the very inception of policy agendas, will assuage public mistrust in new technologies and reinforce the legitimacy of the institutions in charge of their regulation (Bentley, 2005).

Inevitably, this new centrality of the public has been accompanied by the deployment of a range of technologies of elicitation. These are instruments, such as the discussion group, the counseling meeting, or the citizen jury, designed to generate lay views on the issues at hand, and feed those opinions into the policy process. Lay opinions on technoscientific matters are 
typically produced in transient and experimental settings: the small group of individuals assembled in a focus group, the public or semi-public forums in which citizens and experts address each other for a few hours, the slightly more permanent "citizen juries" where stakeholders and citizens aim to work out a common understanding of the issues under deliberation, etc. These assemblies are managed by what Rose has described as "experts of community," social science and psychology professionals deploying the "whole array of little devices and techniques that have been invented to make communities real" (Rose, 1999: 189-90). Technologies of elicitation, and the cohorts of experts that control their application and interpret their results, constitute, a veritable extractive industry, one that seeks to engage publics in dialogue and generate certified "public opinion" with the ultimate goal of increasing the productivity of government.

The purpose of this paper is to analyze, with these considerations in mind, two recent cases of public consultation. Our first example is the public debate on genetically modified (GM) crops conducted in the UK between 2002 and 2004, the so-called "GM Nation?" public debate. ${ }^{1}$ Our second example is a "transparency exercise" carried out in Sweden in 2004 and 2005 on the risks and hazards of third-generation (3G) mobile phones, a consultation formally known as the "Transparency Forum for Mobile Phone Communication." In both cases we have analyzed the documentation generated by these consultations, including some of the internal reports produced by the consultants who designed and managed the exercises. In the case of the Transparency Forum (hereafter TF), we have also followed the conduct of the deliberations in situ. ${ }^{2}$ Our two cases represent in many ways opposite formats of public consultation. The GM Nation? debate was a large public endeavor, intended to provide multiple venues to any citizen willing to make his or her views on GM foods known. The TF, in contrast, consisted of a series of small workshops with "stakeholders," and its primary objective was to facilitate a mutual understanding of their often antagonistic positions.

By juxtaposing these two cases we hope to advance a political analysis of the forms of sociality that underlie public consultations; an analysis that emphasizes "the price to pay ... to create and impose strongly articulated public spaces" (Callon and Rabeharisoa, 2004: 24).

Our two consultations are structured around a distinction between "stakeholders" or "interested parties" (understood as those who already have a view on, or interest in, the issues under deliberation), and the reticent or previously unengaged "general public" (the constituency of those who, at least from the point of view of the organizers, are a priori emptyhanded so far as opinions and interests are concerned; individuals who either have little interest in expressing their opinions, or may even have no opinion to express). In the eyes of the organizers of our two exercises, this distinction was challenged, but ultimately reaffirmed, by the actual experience of confronting concrete publics. As we will argue, the resulting prioritization of the "silent majority" of unengaged citizens over active "stakeholders" gives rise to a curious form of politics: one in which the individuals seen to abstain from participation in political life, what the ancient Greeks would have known as "idiots" (idiōtēs, private individuals who are exclusively dedicated to the privacy of one's own, or idion), become the most highly valued constituency in what is allegedly an attempt to broaden political participation. ${ }^{3}$

Before we flesh out these ideas, let us illustrate our approach to the sociality of public consultation with an example drawn from a different topical and historical context: the participation of the citizenry in the administration of justice.

\section{The eventfulness of public engagement}

In his analysis of social interaction in sixteenth-century Finnish courtrooms, the sociologist Johan Asplund describes some striking forms of citizen involvement in public affairs (Asplund, 
1987). ${ }^{4}$ Visiting court proceedings was something that citizens did regularly in sixteenth-century Finland; it was a normal activity through which one engaged in society as a citizen. In fact, those who refused to attend court proceedings were viewed as anti-social and could be subject to fines.

Yet, the citizens who attended court proceedings did not simply provide an audience to the proceedings. They were forceful and vocal, and their presence was instrumental to the very administration of justice; with their behavior in the courtroom they could confirm or challenge the judge's verdict. Asplund describes how, already on their way to the courtroom, people began to quarrel with, insult and abuse each other. Once in the courtroom, they not only hurled abuse at the defendant or the plaintiff, depending on their sympathies, but made lawyers and judges the target of their attacks. And these attacks were not merely verbal. As Asplund writes:

In 1591 Marjatta Hannuntytar was so furious over the verdict of the panel of "lay assessors" that she burst into the courthouse and attacked one of the assessors and tore his hair with both her hands. If you were not attacking undesirable people, you could destroy whatever came into your way. ... The sixteenth-century Finn was not indifferent in the least. She seems to have been incapable of being nonchalant in the face of her equals. The term "nonchalance" merges a negative prefix with the old French word chaloir, which means warm, eager, urgent. (Asplund, 1987: 50; translated by the authors)

Citizens did not necessarily attend the proceeding with a view or opinion already formed; their reactions were unpredictable precisely because they were shaped by the events and attitudes they encountered during the trial. Asplund uses the term "social responsiveness" to describe this kind of public participation. It refers to an improvised and immediate course of action, as opposed to a controlled, mediated and choreographed response. To be socially responsive is to be immediately affected and moved by the people and things around you and act accordingly. Citizen participation in the Finnish courtroom was vocal, unprompted, unsolicited and unrestrained, and this made the administration of justice a peculiarly eventful occasion. The people assembled in public because their presence mattered; they played a central role in the drama of justice.

In contrast, the Law today appears complete and predictable, uneventful and finished. The actors involved in its workings are assigned clearly defined roles. "All parties act as if they were not engaged in the proceedings at all; strictly speaking, as if they were not present at all. If there is 'affection,' it appears as an inner state, which only occasionally and fastidiously is let out" (Asplund, 1987: 53-4). If the public were to burst into shouting and screaming, order would be called, or the meeting would simply be called off. The riotousness of a sixteenth-century Finnish courtroom does not belong in our space of judicial administration.

This is particularly clear if we compare Asplund's description of the sixteenth-century courtroom with our best contemporary example of citizen participation in the administration of justice: the jury. The jury is first and foremost an audience, in the literal sense that its main form of sociality in the courtroom is to listen to what the parties and their spokespeople have to say. Jurors not only are carefully screened, but their participation in the courtroom is highly choreographed: their involvement is managed to be as uneventful as possible, beginning with their preliminary interrogation (and, possibly, their pre-emptive exclusion). Crucially, jurors are silent during the hearings; they rely on lawyers and judges to extract the information they will use in their private deliberations; even when they are entitled to ask questions they rarely make use of their right. Often they are isolated to protect them from interfering influences, and their discussions are confined to a secluded space, the "jury room." ${ }^{5}$ There is a fundamental rationale for this sanitization of citizen involvement: the complex rules and protocols that accompany jurors from the moment they are called to serve their duty to the point where they declare a verdict are meant to safeguard the quality of each 
juror as a representative of an idealized citizenry, to make each juror interchangeable with any other juror, and to transform the jury into a machinery of abstract justice. Formalization is expected to maintain a certain "accuracy of reference" (Latour, 2004)—in this case, a stable justice, as defined by a sample of the citizenry. ${ }^{6}$

This brief excursus into citizen engagement in sixteenth-century Finnish courtrooms serves us to introduce the dimensions of public participation that will structure our analysis of the two consultation exercises. Public participation entails particular forms of sociality, and every act of citizen involvement in public matters can be defined by its degree of eventfulness. The term "consultation" suggests a highly formalized and carefully choreographed form of engagement. Citizens are expected and sometimes forced to act in accordance with previously conceived roles, and their participation is channeled to the production of a predictable, "fair" outcome. The purpose of the consultation is to generate a stable referent ("justice," "public opinion"), and the foremost measure of the success of the exercise is the accuracy in reaching this referent.

And yet, enticing the public to take a position on controversial issues can also give rise to a form of social responsiveness that overcomes the bounds of mere "consultation." It can generate surprises, unanticipated events. We now turn to our two cases, the British public debate on GM foods and the Swedish transparency exercise on mobile telephony. We organize our analysis sequentially, beginning with the design of the two exercises, continuing with the problems of their conduct and management, and concluding with the production of material outcomes out of the processes of elicitation.

Our two examples addressed technologies — food biotechnology and mobile telephonythat have generated protracted and raucous public debate. The governance of food biotechnology has undergone a series of radical changes, and the last decade has witnessed the creation of a plethora of new regulatory and semi-regulatory bodies in Europe. It was one of these novel institutions, the UK Agriculture and Environment Biotechnology Commission (established in 2000), that recommended the conduct of a wide-ranging public debate on the future of GM crops. ${ }^{7}$ The GM Nation? public debate was launched in July 2002 under the supervision of a Steering Board composed largely of academics and non-affiliated experts.

Disputes over the radiation caused by the mobile phone infrastructure have raged for decades, generating a well-established scientific doctrine on the thermal effects of non-ionizing radiation on humans. While public anxiety over $3 \mathrm{G}$ telephony has given rise to new kinds of scientific uncertainty over the non-thermal effects of the mobile telephony infrastructure, the technical dimensions of these concerns have largely been ignored in the policy debate (Stilgoe, 2005: 62; Drake, 2006). As a response to a widely spread public concern over the radiation provoked by $3 \mathrm{G}$ transmitters in Sweden, the Swedish Radiation Protection Authority (SSI), the agency in charge of determining acceptable levels of radiation, decided to assemble in a "transparency exercise" some of the stakeholders in the $3 \mathrm{G}$ debate, including groups highly critical of mobile telephony. The SSI had previous experience in responding to public mistrust in new technologies. In the 1980s and early 1990s, when the national nuclear waste program met vocal local protests, the SSI tried to improve the quality of communication with stakeholders by emphasizing broader participation and deliberation.

\section{Designing the encounter with the public}

The UK debate and the Swedish forum were premised on predefined communication models that included criteria for the selection of relevant participants and, concomitantly, rules of exclusion to screen out unwelcome members of the public. The fundamental distinction that 
guided the organizers was that between the "general public" (sometimes referred to as the "silent majority") and "interest groups" or "stakeholders." In the view of consultation organizers, the former are characterized by the fact that their views are deemed unknown, or nonexistent, prior to the consultation. The latter, on the other hand, are perceived as already possessing a preformed position on the issues at hand, and it is around this position that their particular identity has taken shape.

The GM Public Debate was organized to promote public deliberation on the future of agricultural biotechnology, and to do so in accordance with the public's own interests and questions; to listen to the public in the broadest, most unstructured way possible, so as to allow the public's own concerns and frames to emerge. The "terms of reference" of the Steering Board stated that the debate ought to pay special attention to the views of "people at the grass roots level whose voice has not yet been heard," and should also "provide meaningful information to Government about the nature and spectrum of the public's views." Thus, from the outset the debate was meant to be both a forum for open-ended discussions and a fact-finding exercise; a space for deliberation and a research tool able to unearth the public's true attitudes towards biotechnology. These two goals-deliberation by the public and research on the public-proved difficult to combine.

In order to frame the debate along the lines of the public's own concerns and interests, the Steering Board decided to conduct a series of preparatory discussions known as the Foundation Discussion Workshops (FDW). Groups of 18 to 20 carefully selected individuals were given an opportunity to discuss food biotechnology in an open-ended way. The goal was to discover the concerns and questions that animated the views, or lack thereof, of ordinary citizens, and to use this information to structure the debate, thereby thwarting the tendency of previous consultation exercises to address the questions and concerns of the consultants, rather than those of the consulted. The consultancy firm hired to run the FDW used a combination of Heideggerian phenomenology and client-centered Rogerian psychotherapeutic practice, in order, as the experts put it, to allow each and every participant "to engage without having to adopt ways of being that are alien to him":

This approach enables participants to engage with the topic(s) of discussion with the minimum of prior framing by the researchers. The concerns and interests of participants are tracked and followed throughout the Workshop process, and the energy with which these concerns and interests emerge is used to guide subsequent questions, exercises and interventions. Thus participants are provided with a great deal of ownership of the process and how the process is structured. (Corr Willbourn, 2003a: 7)

This desire to draw topics and opinions out of the participants' own frames of reference was accompanied by a parallel attempt to exclude, or at least segregate, individuals or groups with already-formed views. These were the people who had already been heard in the long and rowdy debate over GM foods. The public debate had set out to listen to "ordinary citizens," defined by the consultants as individuals who had no "prior allegiance with, or connection to, GM" (Corr Willbourn, 2003a: 8).

The distinction of these two kinds of publics was evident in a separation already enacted in the preparatory workshops. Along with the seven foundation workshops composed of "ordinary people," the consultants assembled a group of activists in a separate group that came to be known as the Actively Involved Workshop. The separation was reflected in the consultants' later interpretation of the discussion groups' dynamics. While the seven groups of ordinary individuals seemed happy to frame their discussion in terms of questions posed to the organizers, the meeting of the already "actively involved" proved to be unavoidably confrontational. "As soon as the substantive issues surfaced," a report pointed out, "powerful 
disagreements were expressed" (Corr Willbourn, 2003a: 68-73). The ordinary citizens, in contrast, appeared more malleable; they could be affected by the process of deliberation itself.

The Swedish TF could not have had a more different goal. Rather than targeting the general public or "ordinary people", its key constituencies were the already configured "stakeholders" in the mobile telephony debate. The form and content of the exercise was decided "in cooperation with all concerned parties." The mandate of the deliberation was open-ended which, according to the organizers, was one of its most appealing characteristics. The communication model used to guide the dialogue was based on Habermas's theory of communicative action, and its basic principle was that broad participation, impartiality and fairness-i.e. allowing a wide range of participants and perspectives to effectively influence rules and agendas - would be conducive to a fruitful exchange of views.

SSI began the preparations for the TF by appointing a reference group whose members were drawn from relevant national authorities, local governments, the mobile telecommunication business, and two "critical” groups: Vågbrytaren (the Wave Breaker), an environmental organization opposed to the increase of electro-smog in society, and the Swedish Association for the ElectroSensitive. Electro-sensitivity is a term used to describe a variety of symptoms (a burning sensation in the skin, nausea, headache etc.) that those afflicted associate with their exposure to electric and magnetic fields (EMFs).

Thus, unlike the GM Nation? debate, the purpose of the forum was not to articulate the unheard voices, but to enhance dialogue between various well-known actors. The reference group assembled by the SSI discussed possible mechanisms for allowing the general public to participate in the debate. The original plan of the SSI and their commissioned consultants had been to conduct a series of seminars with the stakeholders as a preparatory phase for a second stage in which the wider public would be involved. However, when the ElectroSensitives and Vågbrytaren rejected the offer of the telecommunication industry to finance this second phase of the debate the plan was abandoned. In spite of the fact that the consultation was thus limited to "stakeholders," the distinction between "interested parties" and the "silent majority" was still operative in the discussions and reflections generated at the TF. It was clear that the organizers took for granted that the participants were not really representative of the "general public," a constituency they evidently thought was important to reach. The following discussion between two of the consultants managing the discussion (C1 and C2), members of Vågbrytaren $(\mathrm{V})$, a representative of the mobile industry (MI), and a public health expert (E), shows how this general, and absent, public figured in the deliberations: ${ }^{10}$

C1: How do we reach the silent majority?

V1: The question is why this majority is silent. Those who worry the most are the most enlightened.

$\mathrm{C} 1$ : This majority has another view on risk perception and is an important group in this context. Can you make panel surveys to reach the opinions of the majority?

C2: There are many methods and panel surveys and focus groups are just two of them. We must not forget that [during the second TF] many elected politicians were there and they represent the public.

MI: Vodafone has an investigation over public risk perceptions. We can look at the available material.

V2: It is very questionable to use material that comes from Vodafone.

E: It should be used. We can look at the questions it raised; it can provide some of the pieces of the puzzle ...

While the GM debate tried to reach the "general public" through focus groups and a careful segregation of participants ("ordinary" versus "actively involved"), in the TF the abstract 
general public was present in the discussion largely through its absence. It was a referent always lying outside the discussion, an unreachable point of fugue that nevertheless shaped the deliberations and, as we will see, affected the weight of the evidence generated by the consultation.

\section{The conduct of debate}

In their design, the two consultation exercises followed particular models of the targeted public, and of the best way of reaching it. These models prescribe a series of roles for the participants, often schematic versions of general philosophies of communication. Yet, the formalized attributes and expectations are quickly confronted with the reality of the consultation meeting.

The key venues of the GM debate were the public meetings held throughout Britain in June 2003. Six large events took place, organized by the Steering Board itself. There was a second tier of around 40 regional and local meetings, and a third tier of over 600 local meetings, organized by local volunteers. The debate included other venues of public participation: the official website received 2.9 million hits between 1 June and 16 July (24,609 unique visitors), and 36,557 feedback forms were submitted. The organizers received over 1,200 letters and e-mails.

The fundamental problem for the organizers of the GM debate was how to balance the fundamental reliance on public events, attended by people who were not previously screened, with the stated desire to focus on individuals with no prior opinion-people, in other words, who were unlikely to voluntarily show up at a public event to discuss these issues. The search for "ordinary people" led some to question from the start the validity of the public meetings. The presence in these public events of a majority of vocal, self-selected individuals was seen as an insurmountable methodological problem. "It does concern me," a member of the Steering Board told the press after the first public meeting, "that people are using this as a platform to publicise their views." "A number of people," another Board member argued, "are just here to say something through a microphone."11

Some newspapers adopted the same interpretation of the open discussions. An article published after the first meeting described the event as "a unique experiment to find out how ordinary people think," but pointed out that the "only blemish on such noble intentions was the absence ... of ordinary people." ${ }^{2}$ This view of the public events was substantially replicated, and officialized, by the House of Commons' inquest into the consultation. As the Chairman of the Committee of Inquiry put it in his first question to the Chair of the Steering Board during the parliamentary hearings:

I suppose the main criticism of this process was that necessarily it was always going to be hijacked by people who were basically campaigning for one argument or the other argument, and what one might call the ordinary "punter" either did not express a view or found it difficult to express a view in the light of the way feelings were being expressed and one could have predicted the outcome before it started. (HC Environment, Food and Rural Affairs Committee, 2003: Ev. 1)

In this interpretation, which appears almost preordained ("it was always going to be hijacked"), the public meetings served largely as a venue for stakeholders and activists to express well-rehearsed arguments, rather than for "ordinary people" to engage unconditionally in open-ended deliberation. ${ }^{13}$ To control this bias in the public events, the organizers announced that they "were also canvassing views from carefully-selected focus groups, who would form the control against which to compare views from the wider public debate." 14 
This resulted in a parallel strand of the GM Nation? debate known as the "Narrow but Deep" component. It continued the model of the "foundation discussion workshops," and consisted of ten small focus groups, with seven to eight participants each (hence the "narrowness") who met twice, once for an introductory meeting, and again two weeks later to assess the effects of the participants' deliberation (hence the "deepness" of the exercise). Participants were asked to keep a diary of their personal investigations and reflections on the GM issue between the two meetings. The organizers hoped to allow participants' opinions "to mature and to change," and to be able to trace this progress or evolution, and they asked participants to keep a "daily diary" of their personal investigations and reflections on the GM issue between the two meetings.

To ensure that the "narrow but deep" element consisted only of ordinary people, the consultants used a recruitment questionnaire. Several kinds of individuals were excluded from participation: those who had already participated in research or group discussions on topics related or similar to GM, and those who during the previous five years had worked in advertising/market research/journalism/public relations, the biotechnology industry, scientific research into gene technology, or in a campaigning organization or any other group concerned with biotechnology. ${ }^{15}$ As for farmers or those in the agricultural sector, only individuals who professed to "have a completely open mind" about GM crops were allowed to participate.

As the screening rules make clear, the "narrow but deep" meetings were meant to represent a "general" public, to constitute a body of interchangeable citizens willing to engage in the discussion agenda presented to them by the organizers. Not surprisingly, the conduct of the "narrow but deep" meetings helped solidify a particular view of the attitudes of the "general public" towards GM crops. Three key ideas were made clear by the "narrow but deep" meetings: (1) that a majority of participants becomes increasingly concerned and negative about GM over the course of the deliberation exercise; (2) that participants form and express more opinions as they immersed themselves in the issue (i.e. the number of "don't knows" was significantly reduced from the first to the second meeting); and (3) that the more knowledgeable "ordinary" people become, the more likely they are to believe that relevant knowledge about the effect and implications of biotechnology was lacking.

But it was specifically the mobility of the participants in these discussions that struck the organizers as their most remarkable characteristic. Participants in the discussions were noticeably moved by the experience. The movement did not constitute, the consultants emphasized, a linear progress, "a straight line, from recruitment at the beginning through information gathering and deliberation to conclusion." The path of their evolution could be compared to "a line that traced a circular path, starting at attitude on recruitment, circling out into questioning, information gathering and deliberation and coming back towards the original position before going out on another circuit" (Corr Willbourn, 2003b: 56). In their report to the Steering Board, the consultants' dwell on the trope of movement:

This curve would be traced many times. This is illustrated by the fact that a great deal of what was expressed in the second meetings had been previously expressed in the first meetings or in the work in the Daily Diaries. In some cases wherever the line swung out to, it always passed back over the same point, in other cases it circled out and passed close to, but not directly over the same point, describing a more spiral-like process. For many this tended to lead to a movement overall away from their original opinion-for some this was a slight movement, for others it was more noticeable. Thus most engaged in a recursive process of information gathering and deliberation. For some this either deepened their knowledge or appreciation of their initial intuitive understanding or, more explicitly, reinforced their initial position. Others, however, displayed a noticeable movement that took 
them beyond their initial position-either to a more pro or entrenched anti position. (Corr Willbourn, 2003b: 56-7, emphases in original)

The fundamental aspect of the deliberation is thus, as the authors' own italics make clear, the idea of noticeable movement; the mobility of opinions along a non-linear path. Regardless of whether they reached positions different from the ones they started from, participants displayed a perceptible, traceable movement in their attitudes towards GM foods. The path might be circular, but it is not repetitive: it is recursive, or spiraling. The deliberation displaced the participants and turned them into mobile entities. The participants in the "narrow but deep" strand obeyed what is, in the eyes of the consultants, the fundamental moral imperative of deliberation: they allowed themselves to be moved (Callon and Rabeharisoa, 2004), in stark contrast with the immobility and rigidity of the positions expressed in the public meetings.

The Swedish Transparency Forum on mobile phones was arranged on very different premises. A small number of participants took part in three discussion workshops. The first meeting comprised some 40 participants and lasted a full day, while each of the two subsequent meetings lasted two days and involved around 60 participants. The three meetings were held in or around Stockholm, and the participants were largely from this area. The size and format were partly a consequence of the lack of funding, and the organizers were willing to accept that the final arrangement constituted a sort of "mini TF."

The TF organizers had made an effort to bring together highly polarized groups, and from the start disagreements were thus clearly visible. This very fact, however, moved participants, albeit in a different fashion from that described in the reports on the GM debate. The discussions did not lead the stakeholders to change their positions in any visible way, or to trace anything resembling the "recursive process" of the "narrow but deep" meetings. But the heated and antagonistic atmosphere moved participants emotionally. The mere presence of groups holding radically opposing views in the same room, and the need to engage with them, could have intensified the clash of views and the sense of insoluble conflict, but there is also evidence to the contrary.

The format of the three TF seminars was a mix of small group discussions and plenary sessions, presentations and interrogations. It was assumed that the participants had well-articulated opinions and possessed a relatively stable set of identities before they entered into the consultation. Yet, even in such a highly staged event, an element of surprise and a degree of eventfulness could not be completely excluded. Take for instance the discussion over the phenomenon of electro-sensitivity. The members of ElectroSensitive, with their deeply held convictions about the correlation between their illnesses and exposure to EMFs, faced opposing but similarly strong views about the non-existence of such correlation. During lunch, and in small group discussions at the margins of the official meetings, representatives of regulatory authorities and mobile phone companies made comments to the effect that the identity at the heart of the electro-sensitives (and the main reason for their presence there), was at best questionable. "The only thing that could help [the electro-sensitives] would be cognitive behavioral therapy," a participant said. "It can be a problem to be too complaisant to their demands, since that is in fact to admit that they are right," another argued. ${ }^{16}$

On the other hand, on several occasions the same actors who denied that the phenomenon of electro-sensitivity actually existed acted as if it did. The first TF seminar was held in a place chosen for the benefit of the most severe electro-sensitives. ${ }^{17}$ The first thing participants did upon entering the meeting was to turn off their mobile phones, wrap them in aluminum foil, and put them in a box outside the building. They had to do the same with their electronic car keys (after they had moved their cars further away from the building if they were parked too close). As one of the consultants put it, "We were actually rather complaisant" [towards the demands 
from the electro-sensitive]. ${ }^{18}$ That is, even though some of the participants entered (and exited) the TF meeting denying openly the very phenomenon of electro-sensitivity, they acted respectfully towards the demands of other participants. In this sense, the TF meetings caused some movements in the actors' previously defined positions, at least temporarily. After the first TF event, a representative of Vågbrytaren, referring to the representatives of the mobile phone operators, pointed out that "some of them were actually rather touched; they are beginning to realise that this is real. But it is difficult to tell how it affects them in the long run." 19

Yet, from the point of view of the organizers, what characterized the TF was still the polarization between those who were "critical" and those who were "uncritical" of the existing regulations on mobile phone radiation. This forced the organizers and the reference group to address two types of problems. ${ }^{20}$ The first was how to balance the two sides of the debate-which experts to invite and how to keep a balance between researchers on the critical side and those on the uncritical side. After the second TF seminar an SSI official admitted that "there was a strong bias ... We had hoped that the composition would be more heterogeneous, many expressed the same critical opinions." ${ }^{21}$ Second, the stated intention to "reach a better understanding" and to enhance dialogue between polarized groups presented the organizers with constant challenges in the administration of the deliberation. Established rules for producing a good dialogue had to be made explicit to the participants repeatedly, and the organizers had to continuously rebuke participants who deviated from the rules. This occurred when voices were too sharp and the discussions turned into what the consultants termed "debate" (characterized, in this view, by antagonistic parties trying to win over each other), rather than "dialogue" (in which participants listen and try to understand each other). On one occasion the moderator plainly told participants that the heated exchanges were obstructing a "good dialogue" from taking place. ${ }^{22}$

The effort to control the events had varying degrees of success. In one instance, the rules for the achievement of a proper dialogue were explicitly stated by the moderators (to avoid sarcasm and leading questions, to give suggestions and supportive responses to others, etc.). In addition, the various parties were asked to appoint a group leader to ensure that the rules were followed. However, the participants often ignored these rules-by not appointing a group leader, or by making aggressive assertions, such as provocatively placing on the table evidence supporting their case. ${ }^{23}$ The desire of the organizers to formalize the formal procedures of the TF was related to the expectation that all parties would listen to each other and be affected by each other's arguments - to the point, perhaps, of being willing to change their minds. The organizers wanted the participants to be moved by the experience of deliberation, and reacted strongly - explicitly restating the rules of the game-when they felt the anticipated dialogue degenerated into mere debate. The organizers faced an implicit choicebetween adjusting their model of preferred communication to the actual process of exchange or adjusting the participants to their predefined conception of the adequate debate - and generally opted for the latter.

\section{Material outcomes: the de-mobilization of the public}

In principle we can identify three potential outcomes of a consultation exercise. We have mentioned the first one: the changes in attitudes, emotions and positions of those who undergo the process, including the organizers. The second outcome is a more material one: the documents and other written accounts that emerge from the consultation, and particularly the final report attempting to officialize a singular meaning for the exercise. The third possible outcome is more difficult to ascertain. It concerns the effects of the consultation on those who did not participate in it, specifically its influence on governmental policy, and on the 
strategies of the "interest groups" involved in the controversy. Assessing this kind of influence would require an analysis of policy changes and mobilization strategies in the aftermath of the consultation, something we cannot provide here. This section will recapitulate our ideas about the mobility of participants, and describe the official reports and evaluations that emerged from our two deliberative exercises' .

We have already discussed the effects and affects of public deliberation and its ability to move the actors involved. As participants engaged in information gathering they could remain static in their positions but could also be taken beyond them. The "narrow but deep" discussions in the GM debate were described by their organizers as generating a very noticeable kind of mobility in contrast to the large public meetings, which were described as dominated by fixed, static positions. The Transparency Forum enrolled actors with previously identified views (and on the basis of those views), and would seem to have caused only a slight and humbler kind of movement, one that brought participants closer to each other and made future contact easier, even if their opinions were still polarized. Referring to the "critical groups," an SSI official stated that "at least we have established a contact with some of them and realized that they are serious and really worried about this ... In the future, when SSI is planning new recommendations we can gather these groups again." ${ }^{24}$

Beyond the effects on participants, the most tangible outcomes of our two cases were the written reports through which organizers officialized a particular meaning of the consultation. The GM Nation? official report was released by the Steering Board in September 2003. An official evaluation of the TF, conducted by professional evaluators commissioned by the SSI, was ready in February 2006. The TF evaluation was meant to be released in conjunction with the official TF "report," but the purpose and content of this report became a matter of dispute, and, as of April 2007, it has not yet been released. We will thus focus on the official report of the GM debate and the official evaluation of the TF to try to understand the dynamic force of such documents.

The fundamental purpose of the official report of the GM debate was to bring together, and give coherence to, the multiple strands of the consultation, to extract a single narrative on biotechnology and the public from the multifaceted experience of the debate. The central problem was how to integrate what the report itself identified as two rather different sources of evidence: on the one hand, the opinions expressed by the "self-selected" participants of the public meetings (and those, similarly "self-selected," who had sent letters and feedback forms), and, on the other, the views of those carefully chosen individuals who had participated in the "narrow but deep" discussions. The report tried first to emphasize the commonalities between the views and attitudes expressed in the public and private settings:

We found that the content of the debate was very similar right across each spectrum. Whether they write a letter or an e-mail, or visit the website, or express themselves in a meeting, or sit down with each other in a deliberative process, people raise the same types of issues and concerns about GM. They use the same kinds of arguments whether they are asked to think hard about the issues or choose to express themselves from the top of their head. (Steering Board, 2003: 38)

However, in uneasy juxtaposition to this effort to produce a single narrative, the report devotes most of its space to teasing out the specific lessons to be drawn from each venue of participation. The report establishes a distinction between the kinds of opinions expressed in the public events, and those articulated in the closed meetings — and, more importantly, between the kinds of people who expressed them. This distinction is based on a fundamental assumption: that GM is an issue "far removed from ordinary life and the mainstream of current politics" 
(Steering Board, 2003: 79), that it "is not a salient issue in most people's ordinary lives" (p. 97). From the premise that ordinary people are not unduly concerned with the issue of GM foods, the report logically deduces that those individuals who took an active interest in the debates and volunteered their participation must be special and not representative of the "general" public. Obviously, if one begins by assuming that ordinary people rarely think about GM "in their daily lives" (Steering Board, 2003: 15), one can easily deduce that those who attended the open meetings must be extra-ordinary, and therefore unrepresentative. A similar conclusion is drawn with respect to those who made the effort to write a letter or send an e-mail to the Steering Board: "They are also unusual people. ... GM is not a salient issue in most people's ordinary lives. If it is unusual to write a letter for publication about anything, it is fair to suggest that it might be even more unusual to write a letter about GM" (Steering Board, 2003: 97). Furthermore, these extra-ordinary people were easily characterized as having established, entrenched views, in contrast to the participants in the "narrow but deep" discussions, who came to the meeting with "no fixed position on GM" (Steering Board, 2003: 94).

The official evaluation of the TF on mobile telephony presents important differences with respect to the report of the GM debate, differences that reflect the dissimilar goals and scope of the exercises. The fundamental purpose of the TF evaluation was to present the dynamic process and the open and participatory working method that characterized the discussions among stakeholders. The aim of the TF had been to improve dialogue and illuminate opinions on mobile telephones, and the ideal result for the organizers would be the evidence of a "multiplicity of questions raised," rather than any singular narrative or set of univocal answers. ${ }^{25}$ Thus the primary ambition of the document was not to give a coherent picture of the participants' views on mobile phone technology, but rather to present the method of dialogue, the specific mode of conduct of the seminars, and the forms of exchange that characterized the interaction of participants. The emphasis was on the methodology of deliberation and its virtues.

This methodology prescribed that the participating stakeholders should be involved in the formulation and writing of the final report, that the document that would bring closure to the exercise ought to be the result of the work of all the actors involved in the forum. This led to some unanticipated problems. Representatives of Vågbrytaren and the ElectroSensitives, for instance, carried out a thorough and time-consuming effort to compare the formulations proposed in the draft report with tape recordings of the actual discussions, and concluded that the phrasing of the former had sometimes been subtly changed to the advantage of the SSI and the disadvantage of Vågbrytaren and the ElectroSensitives. ${ }^{26}$

While the final report suffered never-ending delays, the evaluation commissioned by the SSI (and based on interviews with the participants) became the only available document offering an "official" interpretation of the consultation. The evaluation described the impact of the deliberations on the participants as "perishables," fragile gains in need of attention in the near future:

Our results show that the aim of the project has been partly reached. The project has made an impact, mainly at the level of individual participants ... The positive effects achieved are to be treated as perishables. SSI, as the driver of the project, has in practice a special responsibility in this context and also an opportunity to maintain a continued dialogue and actively demonstrate that it has listened to other actors. We believe SSI should act to create some kind of forum for continued dialogue, drawing on the experiences from Transparency Forum. (TF Evaluation, 2006: 3-4; original quote in English)

The key to these positive effects was the face-to-face meetings and the personal relationships that emerged and evolved throughout the consultation. It is not surprising that the evaluators would stress this dimension of the exercise, since the evaluation was commissioned to assess 
the discussions in light of the communication model employed by the organizers, a model that emphasized the value of personal contact and informality in the production of mutual trust. Indeed, the elaboration of the TF evaluation can be interpreted as a way of improving the correspondence between the model employed to design and organize the consultation and the conclusions that would emerge from the exercise.

Finally, we would like to discuss the response of the respective governments to the consultations. (In the case of the TF, and since the SSI is an independent expert authority responsible for this policy field, it is in particular the agency's own responses on the TF that are interesting in terms of policy outcomes.) After launching the GM debate, the UK government promised to respond in writing to the conclusions of the debate, in the hope that this "will reassure the public that their participation is worthwhile." 27 The response was issued by the Department for environment, Food and Rural Affairs (DEFRA) in March 2004. The document was a joint response to the three reappraisals of biotechnology that had just taken place- the GM Public Debate, the Scientific Review, and the Economic Assessment of GM crops. The decision to respond to the three strands in a single document proved important: the government was thus able to "weigh up" the evidence from the three processes, and to find in the Science and Economic reviews responses to the "concerns" expressed by the public in the public debate.

The government's response construes the public debate as, fundamentally, a research exercise. It "has helped to improve our understanding of what people really think about GM crops" (DEFRA, 2004a: 11). The debate was no longer an open-ended deliberation process but primarily a fact-finding enterprise, guided by an ideal of accuracy, and meant to discover the stable "concerns" and fixed "anxieties" that dominate the public's imagination of GM foods. The government "recognized" these concerns and pointed to the different ways in which the existing regulatory process already responded to the fears raised in the discussions. "We have looked at these concerns carefully," the government wrote, "and we have concluded that for the most part the regulatory regime which is now in place is capable of addressing them, but that on some issues further action is required" (DEFRA, 2004a: paragraph 4.9).

The ability of the government to describe the public debate as expressing a series of stable concerns is based on the sharp distinction between the open and the closed strands of the debate, a distinction that the official report of the debate had helped solidify. In its response, the government quoted paragraphs from the report to support the claim that the participants in the open and closed meetings represented radically different constituencies, and that only the latter, the carefully screened individuals enrolled in the "narrow but deep" groups, offered an accurate representation of the general public's attitudes towards GM foods. According to the government, the "narrow but deep" strand "enabled the debate process to take account of the views of those members of the public who might not normally have chosen to take part, in contrast to the "self-selecting' participants in the debate," and represents "one of the more successful features of the debate, serving as an important 'control' on the findings of the open process" (DEFRA, 2004b: paragraph 23).

We have to take the term "control" in the above sentence in its most literal sense: the government used the evidence of the closed sessions to neutralize the open meetings and the generally critical attitude towards GM foods that transpired there. Rather than vocal opposition, the government argued in its response, "the predominant feeling among the Narrow-but-Deep sample was one of uncertainty and this was largely because they felt uninformed" (DEFRA, 2004a: paragraph 3.3).

The citizens that participated in the "narrow but deep" discussions, and by extension the "general public," appear as more malleable constituencies, less inflexible and categorical than the stakeholders or self-selecting "activists" of the open meetings. They lack a definitive commitment to either side of the debate, and are characterized by a sense of uncertainty and an 
openness to learn (and, correspondingly, to frame their participation in the form of questions, rather than opinions). This is a far more promising public for a government seemingly bent on leaving the regulatory regime for GM crops unaltered. But there is an interesting paradox here. Whereas the debate organizers used the "narrow but deep" groups to generate a mobility of opinions, to produce a trajectory of deliberation, the government's response relies on these discussions to produce a static image of "public concerns" as a set of fixed and clearly identifiable attitudes. The discussion groups were particularly useful to the consultants because they managed to move the participants. Yet, the government was keen to present their views as stable and static. The open meetings had been criticized for being dominated by a set of stationary viewpoints, but in effect a very similar image of public opinion as an inert entity characterizes the government's response to the deliberation process.

Let's now turn to the TF. The response of the SSI to the official evaluation has been to state formally that it will follow the recommendation of the evaluator to foster a continuing dialogue with the stakeholders and preserve the "perishables" obtained from the first round of dialogue. ${ }^{28}$ If the SSI manages to continue the discussion, it will have succeeded in further mobilizing the groups critical to mobile telephony. This would likely be more beneficial to the SSI than to Vagbrytaren or the ElectroSensitives: vague calls to dialogue are often more valuable to the organizers of the debate than to those invited to participate. The SSI has been involved in subsequent discussions on these issues. When the Swedish government initiated a new evaluation of its environmental goals, it delegated the work on radiation protection to the SSI, which has invited back all those who were involved in the TF. This devotion to further dialogue does not seem to have had any effect, however, on the SSI's own criteria of risk assessment. In this sense the agency appears keen to mobilize stakeholders in a continuing dialogue on the risks of mobile telephony, but does not seem particularly willing to be itself moved by the process of consultation.

\section{Conclusion: malleable "publics" and the political value of mobility}

Processes of consultation appear very differently depending on whether they are observed from the point of view of organizers and their consultants, or from the perspective of those consulted. For the former, consultation is a process of elicitation, a mechanism for extracting relevant opinions and incorporating them into the process of government. As we have noted, elicitation always depends on shaping, restraining and harnessing particular forms of sociality, often in accordance with theoretical models of what proper communication and citizenship ought to look like. These models are always in play-even when their ostensible purpose is to allow the public to frame the process in their own terms. From the point of view of the consulted, however, consultation always entails action: whether they voluntarily attend a public meeting or are selected to participate in a private discussion, they must necessarily act. And action generates movement and surprises.

Judged from the point of view of sponsors and organizers, the British public debate and the Swedish Transparency Forum represent two possible methodologies for extracting relevant public opinions. In their format, design, content, and expected outcomes they express different models of public deliberation, and divergent mobilization strategies. We have juxtaposed them in an attempt to draw out the generic forms of sociality that characterize these political experiments.

The consultations were structured along a key distinction between a "general public" and "stakeholders." The distinction is based on one fundamental attribute: the possession or not of a set of clearly delineated opinions or interests prior to the process of deliberation. 
Stakeholders are those thought to come to the consultation armed with predefined views. In the eyes of organizers and consultation experts this makes them relatively immobile- their opinions are hardened, their positions entrenched. In the GM Nation? debate stakeholders were often described as "hijacking" the public meetings, using them simply to "publicize their views." The "narrow but deep" groups were assembled to generate the kind of mobility that proper deliberation demands but "self-selecting" participants did not deliver. Anybody with a pre-existent connection or commitment to any particular view on the GM issue was systematically excluded from these meetings. This allowed the organizers to present the selected groups as a more accurate representation of the "general public" and, those who were excluded, as extra-ordinary by definition. It also made it easier to ensure that participants were affected by their involvement in the discussions, and allowed the consultants to trace a visible movement in their opinions.

The Transparency Forum on mobile telephony soon abandoned any hope of representing the "general public," or of altering the opinions of its participants. It attempted instead to elucidate the stakeholders' values and facilitate mutual understanding. It tried to move the stakeholders in a more subtle way: by bringing them together and forcing them to act as if each other's views had some merit, the organizers hoped to make future exchanges easier and keep the flame of "dialogue" alive. Owing to budgetary constraints, the Forum did not make an effort to represent the general public, but this external constituency was a referent towards which the discussion was often oriented. Moreover, its absence certainly diminished, in the eyes of the organizers, the representative value of the exercise-and thus its possible influence on policy.

The value of mobility underlies this distinction between "general public" and "stakeholders" - the latter defined as static, the former as fundamentally movable - and is the central category in our analysis. Yet, the qualities of mobility depend on whether it is observed from the point of view of the consultants or the consulted. For the former, mobility is a desirable, indeed crucial, attribute of participants and their opinions - we saw the satisfaction with which the managers of the GM Nation? debate recorded the trajectory of movement traced by participants of the "narrow but deep" discussions. In a different context and under different constraints, the TF evaluation made clear that the degree to which participants had been moved by the process of deliberation was the fundamental value of the discussion- the reason, beyond mutual clarification, to pursue this kind of exercise.

We can characterize the goal of organizers as mobilization: they want to move participants, to affect them and their views, to generate movement, to break deadlocks. There is a desire to generate narratives of change, even conversion, as the key utility of deliberation and the measure of its productivity; proof that the individuals who come out of the process are not exactly the same who entered it, that attitudes and opinions have been affected by the exchange of viewpoints.

Mobilization looks rather different from the perspective of the participants. Whether they take part in public, open-ended meetings or in highly controlled discussion groups, deliberation is always a form of action. Action implies, first and foremost, movement. Action refers etymologically to the process of "setting something into motion" (Arendt, 1998: 177), and thus entails the making of new and unexpected connections - in Latour's terms (1998, 2004), novel "articulations." As Arendt "The boundlessness of action is only the other side of its tremendous capacity for establishing relationships, that is, its specific productivity" (1998: 191).

This poses a challenge to the models of the public brought to bear on consultation exercises. For instance, the open meetings of the GM Nation? debate were often characterized by a form of "social responsiveness" that did not correspond to the ideal of a proper discussion that guided the sponsors' and their consultants' efforts. It was similarly evident in the 
distinction, emphasized by the managers of the Transparency Forum, between a proper "discussion," in which participants are willing to listen and try to understand each other (to be moved) and a "debate," characterized by antagonism. There is little room in these prescriptive models of deliberation for the agonistic element of debate, or for the possibility that people would be unaffected by discussion and remain in their "entrenched" positions.

Confronted with a contradiction between ideal models of communication and the realities of deliberation "in the wild," organizers do have a choice: to adjust their model to the actual process of discussion, or to adapt the public to the model. The "narrow but deep" meetings of the GM debate are a successful example of the latter. Only in them did the consultants' model of a fully deliberative — and thus highly mobile - individual take concrete shape. But this was achieved by excluding from the proceedings any individual with a commitment to the issue under deliberation. The "man without opinions" was the central character in these meetings, for it was the only one light and malleable enough to be properly moved and mobilized by the consultation exercise.

This reliance on the perfectly uncommitted individual represents a peculiar return to the figure of the idiot, the person with no known opinions or unprompted interest in public matters. In the GM Nation? debate the unengaged became the only legitimate constituency of public deliberation, because they were the only ones who seemed capable of undergoing the sort of conversion that consultants expected. The uncommitted were the only ones who produced the kind of movement that consultants were eager to register. In the famous funeral oration, Pericles noted that "We alone regard the man who takes no part in politics not as someone peaceful, but as someone useless." ${ }^{29}$ The opposite seems to be true in consultation exercises: the unengaged, the quiet citizens, are the most useful of publics, because they are the one authoritative source of representative opinions, and the only constituency weightless enough to be moved by the kinds of consultation exercises and deliberative process that governments and their consultants dream up.

The conflict between different assumptions about publics and their mobilities is expressed in the final reports and evaluations that close the consultation exercise and officialize a particular meaning. When the writing of the final report is shared among the participants, as in the case of the Transparency Forum, difficulties naturally arise: the process of writing becomes indistinguishable from the process of deliberating, which explains the delays in the production of an "official version" of the consultation. The report of the GM Nation? debate offers an opposite example: an official document written by the (very) few-perhaps a single individual — establishing a radical separation between the phase of debate and its write-up. What was often a cacophonous discussion - or, more exactly, a multitude of loosely coordinated ones-is turned, through a dramatic "delegation of speech" (Callon and Rabeharisoa, 2004), into a multifaceted but ultimately coherent story. While the GM Nation? report does its best to capture the diversity of motives, ideas and movements expressed in the debate, it ends up producing a stable image of "the public," and thus a static target for the government's reply. It is striking how the interplay of different mobilities that characterized this multi-pronged exercise eventually was reduced to a stationary model of the public: "ordinary citizens," represented by the few dozen people involved in the "narrow but deep" groups, were characterized as having a set of fixed "concerns." The debate was organized and described in such a way that this transition from movement to stasis became possible and plausible.

We do not want to suggest that consultation exercises, such as the two described in this article, are guided by a hidden agenda and that governments pay only lip service to the need to listen to the public. We are disinclined to simply brush off the rhetoric of consultation as a tactic of "crafted talk," according to which "politicians track public opinion not to make policy but rather to determine how to craft their public presentations and win public support for the policies they and their supporters favor" (Jacobs and Shapiro, 2000: 55). If only because 
this argument implies a distinction between genuine action and symbolic action that we would like to avoid (Blühdorn, 2007).

Instead of searching for hidden motives and real objectives-which would lead us back to interrogations over the "accuracy of reference" whose usefulness for understanding publics we have rejected-we would like to argue that public consultations are processes of mobilization and engines of movement. They may have a purely instrumental objective- to produce utility for government by incorporating "public opinion" into policy-making — but they can and often do become highly eventful: they generate unpredictable movement, of people and issues, and give rise to forms of social responsiveness and articulations that spill over the models of interaction that organizers bring to bear. We would like to suggest that, rather than measuring the success of a consultation on the basis of the accuracy with which it captures a static general public, we should also include among our metrics of political value the way in which they produce new articulations of the issues under deliberation, and the degree of mobility they generate-not only in those who are consulted, but also in those who consult.

\section{Acknowledgements}

This article was conceived and written at the ESRC (Economic and Social Research Council) Centre for the Analysis of Risk and Regulation, London School of Economics and Political Science, and we would like to thank our colleagues there for their comments and criticisms. The article also benefited from presentations at the London Public Understanding of Science Seminar, organized by Martin Bauer and Jane Gregory, and the conference "Organizing the World" (Stockholm, October 2005).

\section{Notes}

1 A thorough evaluation of the GM Nation? debate can be found in the report produced by the "Understanding Risk Team" (A Deliberative Future?). The report is available at: http://www.uea.ac.uk/env/pur/gm_future_top_copy_ 12_feb_04.pdf. For a summarized version, focused on the methodological implications of the debate see Rowe et al. (2005). See also Irwin (2006) for a less normative account of the case and its broader implications.

2 Our study of the Transparency Forum is partly based on having access to the inner sanctum of the deliberation, while our interpretation of the GM Nation? debate draws exclusively on publicly available sources. This analytical asymmetry is compounded by differences inherent in the design and characteristics of our two cases. The GM Nation? debate had a strong public component—-the public meetings served as its most visible face-while the Transparency Forum was a "private" affair, with only selected participants.

3 The term "idiot" did not have in ancient Greece the same kind of pejorative sense it has today, and it is in this non-pejorative sense that we use it here. "Idiot" served to describe a type of individual who, by refusing to participate in political life, by minding exclusively his own affairs, became useless to the polis.

4 Asplund's study is an exegesis and critique of a previous study by the historian Pentti Renvall.

5 The uneventfulness of modern juries is limited to their public performance. Their private deliberations can probably be as heated and emotional as anything a sixteenth-century courtroom ever witnessed.

6 The character of modern juries is linked to their formalized role in the administration of justice. The range of behavior available for the public in the sixteenth-century courtroom was undoubtedly broader-but their influence on the verdict was largely unpredictable. In contrast, juries have to conform to strict rules of behavior and judgment, but they are also guaranteed a very substantial and clearly defined role in shaping the final verdict.

7 The call for a broad public discussion on food biotechnology coincided with parallel reviews of the regulatory situation of GM crops in the UK, including an assessment of the scientific evidence on the safety of genetically modified organisms, and a re-examination of the economic implications of GM agriculture. See www.gmscience debate.org.uk for the documents of the scientific review, and the report "Weighing Up the Costs and Benefits of GM Crops" (Cabinet Office Strategy Unit, 11 July 2003) for the economic evaluation.

8 "Aims and Objectives for the GM Public Debate," available at the official debate website: http://www.gmnation.org.uk/ut_09/ut_9_ex3.htm (accessed 28 November 2006). 
9 Minutes from Preparation Meeting for TF, 17 April 2004, SSI 2004/1828-52. Available at the Swedish Radiation Protection Authority, Stockholm. This and the following quotes from the TF case are translated by the authors.

10 Minutes from the reference group meeting, 16 February 2005.

11 "Public GM views “will count,"” Farmers Weekly Interactive, 4 June 2003. This interpretation of the open meetings as dominated by vocal "activists" is based on the experience of the large, first-tier events. Whatever took place in the hundreds of smaller and largely unsupervised discussions remained largely invisible as far as public accounts of the GM Nation? debate were concerned.

12 "Government's 10-day public road show opens with a whimper," Guardian, 4 June 2003.

13 In this line of criticism, the assumption is that the "activists" are generally those opposed to biotechnology. Those who expounded the views of the biotechnology industry, for instance, were rarely described as "activist" or "self-selected."

14 "Public GM views “will count,"” Farmers Weekly Interactive, 4 June 2003.

15 This exclusion criterion also applied if any member of the family, relative, or close friend of the potential participant had been employed in any of these areas.

16 Second TF, 9 February 2005, observation.

17 At the second and third TF seminar, two of the most severe electro-sensitives participated over the phone.

18 Personal communication with one of the consultants, February 2005.

19 Telephone interview with the member of Vågbrytaren who is responsible for its information and media contacts, December 2004.

20 No participant was explicitly labeled "uncritical." Yet, a consequence of labeling Vågbrytaren and the ElectroSensitives as "critical groups" is that the others are "uncritical" or perhaps "neutral."

21 Interview with SSI official (director for the area of non-ionizing radiation), March 2005.

22 Second TF, observation.

23 Second TF, observation.

24 Interview with SSI official.

25 Reference group meeting, 16 December 2005, observation.

26 Personal communication with representatives of the ElectroSensitives and Vaggbrytaren, May 2006.

27 Letter from Margaret Beckett, 20 January 2002.

28 Strålskyddsnytt, 2006.

29 As recorded in Thucydides, History of the Peloponnesian War.

\section{References}

Arendt, H. (1998) The Human Condition. Chicago: University of Chicago Press.

Asplund, J. (1987) Det sociala livets elementara former. Goteborg: Korpen.

Bentley, T. (2005) Everyday Democracy: Why We Get the Politicians We Deserve. London: Demos.

Blühdorn, I. (2007) "Sustaining the Unsustainable: Symbolic Politics and the Politics of Simulation," Environmental Politics 16(2): 251-75.

Callon, M. and Rabeharisoa, V. (2004) “Gino's Lesson on Humanity: Genetics, Mutual Entanglements and the Sociologist's Role," Economy and Society 33(1): 1-27.

Corr Willbourn Research and Development (2003a) A Report on the Foundation Discussion Workshops Conducted to Inform the GM Public Debate. URL: http://www.gmnation.org.uk/docs/corrwillbourn.pdf (accessed 24 April 2006).

Corr Willbourn Research and Development (2003b) Qualitative Research on a Series of Reconvened Group Discussion for the "Narrow but Deep" Strand of the GM Public Debate. URL: http://www.gmnation. org.uk/docs/cw_final_report.pdf (accessed 24 April 2006).

DEFRA (Department for Environment, Food and Rural Affairs) (2004a) The GM Debate: Government Response. 9 March. URL: http://www.defra.gov.uk/ENVIRONMENT/gm/debate/pdf/gmdialogue-response.pdf (accessed 24 April 2006).

DEFRA (2004b) The GM Public Debate: Lessons Learned from the Process. March. URL: http://www.defra.gov. uk//environment/gm/debate/pdf/gmdebate-lessons.pdf (accessed 24 April 2006).

Drake, F. (2006) "Mobile Phone Masts: Protesting the Scientific Evidence," Public Understanding of Science 15: 387-410.

HC Environment, Food and Rural Affairs Committee (2003) Conduct of the GM Public Debate. Eighteenth Report of Session 2002-02 (HC 1220). London: The Stationery Office.

Irwin, A. (2006) "The Politics of Talk: Coming to Terms with the 'New' Scientific Governance," Social Studies of Science 36(2): 299-320.

Irwin, A. and Michael, M. (2003) Science, Social Theory and Public Knowledge. Milton Keynes: Open University Press. 
Jacobs, L.R. and Shapiro, R.Y. (2000) Politicians Don't Pander: Political Manipulation and the Loss of Democratic Responsiveness. Chicago: University of Chicago Press.

Latour, B. (1998) Pandora's Hope: Essays on the Reality of Science Studies. Cambridge, MA: Harvard University Press.

Latour, B. (2004) "How to Talk about the Body? The Normative Dimension of Science Studies," Body and Society 10(2-3): 205-29.

Rose, N. (1999) Powers of Freedom: Reframing Political Thought. Cambridge: Cambridge University Press.

Rowe, G., Horlick-Jones, T., Walls, J. and Pidgeon, N. (2005) "Difficulties in Evaluating Public Engagement Initiatives: Reflections on an Evaluation of the UK GM Nation? Public Debate about Transgenic Crops," Science, Technology and Human Values 14: 331-52.

STAGE Project (2005) http://www.stage-research.net/STAGE/ (accessed 30 January 2007).

Steering Board (2003) The Findings of the Public Debate. URL: http://www.gmnation.org.uk/docs/gmnation_finalreport.pdf (accessed 24 April 2006).

Stilgoe, J. (2005) “Controlling Mobile Phone Health Risks in the UK: a Fragile Discourse of Compliance," Science and Public Policy 32(1): 55-64.

Strålskyddsnytt (2006) “Transparensforum om mobiltelefoni-detta blev resultatet," Strålskyddsnytt 24(2): 1-6. URL: www.ssi.se

TF Evaluation (2006) “Transparensforum-en utvärdering av genomförandet och effekterna av projektet Transparensforum om mobiltelefoni," Konsultrapport i februari 2006, Faugert \& Co utvärdering. URL: www.ssi.se

Wynne, B. (2001) “Creating Public Alienation: Expert Cultures of Risk and Ethics on GMOs," Science as Culture 10(4): 445-81.

\section{Authors}

Javier Lezaun received his Ph.D. in Science and Technology Studies from Cornell University. $\mathrm{He}$ is a Research Associate at the ESRC (Economic and Social Research Council) Centre for Analysis of Risk and Regulation (London School of Economics), and currently Visiting Assistant Professor in the Department of Law, Jurisprudence and Social Thought, Amherst College. Correspondence: Department of Law, Jurisprudence and Social Thought, Amherst College, 74 College Street, Amherst, MA 01002, USA; e-mail: jlezaun@amherst.edu

Linda Soneryd received her Ph.D. in Sociology at Örebro University and is now based at Score (Stockholm Centre for Organizational Research), Sweden. Her research interests include public involvement and risk regulation and experiments of deliberative inclusive processes. 